\title{
Análise dos haplótipos da anemia falciforme em Fortaleza revela as origens étnicas da população cearense
}

\section{Analysis of sickle cell anemia haplotypes in Fortaleza reveals the ethnic origins of Ceará state population}

Lilianne Brito da Silva'; Romélia Pinheiro Gonçalves²; Sílvia Helena Barem Rabenhorst ${ }^{3}$

unitermos
Haplótipos
$\beta S$-globina
Anemia falciforme

\section{resumo}

Os haplótipos ligados ao gene da $\beta S$-globina foram analisados em uma amostra de 68 cromossomos de pacientes de Fortaleza, capital do Ceará, com anemia falciforme (AF), com a finalidade de fornecer informações sobre a distribuição das frequências dos haplótipos, contribuindo para o estudo das origens da formação étnica da população cearense. A distribuição dos haplótipos do gene da $\beta S$-globina foi $66,2 \%$ do tipo Bantu, $22 \%$ do Benin e $11,8 \%$ do atípico. Houve diferença estatisticamente significativa entre o presente estudo e os resultados de outros pesquisadores no Ceará. A distribuição das frequências dos haplótipos do gene da $\beta S$-globina no presente estudo está condizente com a história da formação da população brasileira. Conforme dados históricos sobre as origens da população negra trazida ao Ceará, o haplótipo Bantu seria o mais prevalente, seguido pelo Benin e Senegal. Estes resultados são relevantes para o estudo das rotas de tráfico dos escravos no Brasil e para entendermos as origens étnicas da população brasileira.

\section{abstract}

In a sample of 68 chromosomes from sickle cell anemia patients from the population of Fortaleza, capital of Ceará State- Brazil, the haplotypes connected with $\beta S$-globin gene were analyzed with the aim to provide further information on haplotype frequency distribution, which ultimately contributed to the investigation into the ethnic origins of the state's population. The haplotype distribution of $\beta S$-globin gene was $66.2 \%$ Bantu type, 22\% Benin type and $11.8 \%$ atypical. There was a significant statistical difference between the results of the present study and those achieved by other researchers in Ceará. The distribution of haplotype frequencies of $\beta$ S-globin gene in the present study is consistent with the history of the Brazilian population origins. According to historical data on the origins of the slave population brought to Ceará State, Bantu haplotype would be the most prevalent, followed by Benin and Senegal. These results are relevant to the study of the slave traffic routes in Brazil and to understand the ethnic origins of Brazilian population. key words

Haplotypes

$\beta S$-globin

Sickle cell anemia

1. Especialista em Hematologia e Hemoterapia; mestranda em Patologia Tropical da Universidade Federal do Ceará (UFC). 


\section{Introdução}

A anemia falciforme (AF) é o resultado de uma mutação pontual (GAG $\rightarrow$ GIG) no códon do gene da $\beta$-globina, conduzindo a uma substituição de ácido glutâmico por valina na sexta posição da cadeia polipeptídica ${ }^{(4)}$ e é caracterizada pela homozigose da hemoglobina $\mathrm{S}(\mathrm{HbS})^{(1)}$.

Os pacientes com AF possuem quadro clínico heterogêneo ${ }^{(2,15)} \mathrm{e}$ entre os fatores que alteram a gravidade clínica da doença está o tipo de haplótipo associado ao gene da $\mathrm{HbS}^{(11,18)}$.

Os diferentes haplótipos da AF estão relacionados com quadro clínico e níveis de hemoglobina fetal (HbF) variados, sendo o haplótipo Senegal associado a níveis elevados de $\mathrm{HbF}(>15 \%)$ e curso clínico menos grave da doença; o Benin, a níveis medianos de $\mathrm{HbF}$ ( $5 \%$ a 15\%) e curso clínico intermediário; o Bantu, ou República Centro Africana, a níveis diminuídos de $\mathrm{HbF}(<5 \%)$ e quadro clínico mais grave; e o haplótipo Árabe-Indiano apresenta níveis elevados de $\mathrm{HbF}$ e curso clínico heterogêneo( ${ }^{(6)}$.

A composição dos haplótipos da AF foi analisada no Ceará por outros pesquisadores, que obtiveram o haplótipo Benin com mais prevalência, não sendo condizente com a história da formação da população brasileira, pois, conforme os dados históricos sobre as origens da população negra trazida ao Ceará, o haplótipo Bantu seria o mais prevalente $e^{(9,14)}$.

O presente estudo teve como objetivo fornecer informações importantes relacionadas com a caracterização molecular dos pacientes com AF em Fortaleza, contribuindo para o estudo das origens da formação étnica da população cearense.

\section{Material e métodos}

Trata-se de um estudo corte transversal em 34 pacientes voluntários, de ambos os sexos, com diagnósticos clínico e laboratorial de AF (forma homozigótica SS), atendidos no ambulatório do serviço de hematologia de um hospital de referência em Fortaleza. O consentimento informado foi obtido de todos os indivíduos e o estudo foi submetido e aprovado pelo Comitê de Ética da Universidade Federal do Ceará (UFC).

A AF foi diagnosticada por eletroforese em $\mathrm{pH}$ alcalino em fitas de acetato de celulose ${ }^{(5)}$ e a presença de $\mathrm{HbS}$ foi confirmada por eletroforese de diferenciação em ágar-fosfato, $\mathrm{pH} 6.2^{(13)}$. O DNA foi isolado de leucócitos, a partir de amostras de sangue total, seguindo o protocolo de Sambrook et al. (1992) ${ }^{(10)}$. A análise dos haplótipos da mutação $\beta S$ foi realizada por meio da técnica da reação em cadeia mediada pela polimerase para polimorfismo dos comprimentos dos fragmentos de restrição (PCR-RFLP), sendo analisados seis sítios polimórficos de restrição, seguindo a metodologia de Sutton et al. (1989)(12): 1) Xmnl 5' $\gamma^{\mathrm{G}}$; 2) Hind III $\gamma^{\mathrm{G}}$; 3) Hind III $\left.\gamma^{A} ; 4\right)$ Hinc II $\psi \beta ;$ 5) Hinc II $\left.3^{\prime} \psi \beta ; 6\right)$ Hinf I 5'ß.

\section{Análise estatística}

O GraphPad Prism (versão 5.0) foi o programa utilizado para a realização da análise estatística e para a comparação da prevalência dos haplótipos do presente estudo com o trabalho feito por outros pesquisadores no Ceará. O nível de significância estatística considerado na análise foi $p<0,05$.

\section{Resultados}

As combinações de haplótipos identificados nos 34 pacientes com AF estudados foram: Bantu/Bantu (50\%), Bantu/Benin (17,6\%), Bantu/Atípico (14,7\%), Benin/Benin (8,85\%) e Benin/Atípico (8,85\%). Dos cromossomos analisados, 66,2\% foram do tipo Bantu; 22\%, Benin; e 11,8\%, Atípico (Tabela 1).

A distribuição da frequência dos haplótipos dos pacientes com AF observada no presente estudo obteve diferença estatisticamente significativa quando comparada com estudo realizado por outros pesquisadores no Ceará $(p=0,0002)$ (Tabela 2).

\section{Discussão}

A AF atinge milhões de pessoas em todo o mundo. Sua presença no Brasil tem sido justificada pelo intenso tráfico de escravos negros provenientes de regiões africanas. Estima-se que nos 306 anos de duração do tráfico negreiro, entre os anos de 1551 e 1857, entraram cerca de 3.500 .000 africanos vindos principalmente das regiões de Angola e Ilha de São Tomé, Costa do Ouro e, em menor número, Costa do Marfim, Costa dos Escravos, Congo, Moçambique, Madagascar e Cabo Verde ${ }^{(7)}$.

O haplótipo Bantu é o mais presente no Brasil, seguido pelos haplótipos Benin e Senegal| ${ }^{(8,16)}$. O haplótipo Senegal 


\section{Tabela 1 Distribuição de haplótipos e cromossomos na população estudada $(n=34)$}

\begin{tabular}{lcccc}
\hline Haplótipos & $N^{\circ}$ de indivíduos (\%) & \multicolumn{3}{c}{$N^{\circ}$ de cromossomos } \\
\hline Bantu/Bantu & $17(50 \%)$ & Bantu & Benin & Atípico \\
Bantu/Benin & $6(17,6 \%)$ & 34 & - & - \\
Bantu/Atípico & $5(14,7 \%)$ & 06 & 06 & - \\
Benin/Benin & $3(8,85 \%)$ & 05 & - & 06 \\
Benin/Atípico & $3(8,85 \%)$ & - & 03 & - \\
Total & $34(100 \%)$ & $45(66,2 \%)$ & $15(22 \%)$ & $03(11,8 \%)$
\end{tabular}

Distribuição da frequência (\%) dos haplótipos típicos da AF em Fortaleza em comparação com estudo realizado Tabela 2 por outros pesquisadores no Ceará

\begin{tabular}{lcccc}
\hline População & $\begin{array}{c}N^{0} \text { de } \\
\text { cromossomos }\end{array}$ & \multicolumn{3}{c}{ Haplótipos (\%) } \\
& & Bantu & Benin & Senegal \\
Presente & 68 & 66,2 & 22 & 0 \\
estudo (CE) & 34 & 41,2 & 55,9 & 2,9 \\
Ceará (CE) & & 34
\end{tabular}

*GALIZA-NETO, G. C. et al., 2005.

AF: anemia falciforme

está irregularmente distribuído no país, consequência do pequeno tráfico de escravos provenientes de Senegal, Gâmbia, Serra Leoa e Guiné(17).

O historiador Pierre Verger descreveu que os escravos da Bahia foram trazidos da região do Golfo do Benin (principalmente haplótipo Benin) e o restante do Brasil recebeu grande imigração de escravos do Congo e da Angola (principalmente haplótipo Bantu) ${ }^{(14)}$. Sobre as origens da população negra trazida ao estado do Ceará, cita-se como advinda, na sua maioria, das regiões de Angola, Congo e Moçambique. Os escravos negros eram introduzidos no estado a partir, principalmente, dos portos de Recife, São Luís e, em menor quantidade, de Salvador e Rio de Janeiro(9).

A composição dos haplótipos da AF foi analisada por outros pesquisadores no Ceará, que obtiveram o haplótipo Benin como o mais prevalente ${ }^{(3)}$. $O$ presente estudo realizado em Fortaleza obteve o haplótipo Bantu com mais prevalência, seguido pelo Benin, em conformidade com dados históricos sobre as origens da população negra trazida ao estado do Ceará. O resultado difere estatisticamente $(p=0,0002)$ do trabalho realizado por Galiza-Neto GC et al. $(2005)^{(3)}$ no mesmo hospital de referência, mas com um menor número de pacientes estudados.

Os resultados atuais são relevantes para o estudo das rotas de tráfico dos escravos no Brasil e para entendermos as origens étnicas da população brasileira, com ênfase na população cearense, evidenciando divergência de dados quanto a analise dos haplótipos em uma amostragem diversificada e em número menor.

\section{Referências}

1. BONINI-DOMINGOS, C. R. Metodologias laboratoriais para o diagnóstico de hemoglobinopatias e talassemias. São Paulo: HN, 2006.

2. BUNN, H. F.; FORGET, B. G. Hemoglobin: molecular, genetic and clinical aspects. Philadelphia: W. B. Saunders Company, 1986.

3. GALIZA-NETO, G. C. et al. Análise dos haplótipos do gene da beta $\mathrm{S}$ globina no Ceará. Jornal Brasileiro de Patologia e Medicina Laboratorial, v. 41, n. 5, p. 315-21, 2005.
4. GONÇALVES, M. S. et al. $\beta$ S-Haplotypes in sickle cell anemia patients from Salvador, Bahia, Northeastern Brazil. Braz J Med Biol Res, v. 36, n. 10, p. 1283-88, 2003.

5. MARENGO-ROWE, A. J. Rapid electrophoresis and quantitation of haemoglobin on cellulose acetato. J Clin Path, v. 18, p. 90-192, 1965.

6. NAGEL, R. L. The origin of the hemoglobin S gene: clinical, genetic and anthropological consequences. Einstein Quarterly Journal of Biology and Medicine, v. 2, p. 53-62, 1984. 
7. NAOUM, P. C.; DOMINGOS, C. R. B. Doença falciforme no Brasil: origem, genótipos, haplótipos e distribuição geográfica. J Bras Patol, v. 33, n. 3, p. 145-53, 1997.

8. PANTE-DE-SOUZA, G. et al. Origin of the hemoglobin $S$ gene in a northern Brazilian population: the combined effects of slave trade and internal migrations. Genet $\mathrm{Mol}$ Biol, v. 21, p. 427-30, 1998.

9. RIEDER, O. O escravo no Ceará. In: Coletânea. Da Senzala para os Salões. Ceará: Secretaria de Cultura, Turismo e Desporto, 1988.

10. SAMBROOK, J.; FRITSCH, E. F.; MANIATS, T. Molecular cloning: a laboratory manual. New York: Cold Spring Harbor Laboratory Prees, 1989.

11. STEINBERG, M. Modulation of fetal hemoglobin in sickle cell anemia. Hemoglobin, v. 25, n. 2, p. 195211, 2001.

12. SUTTON, M.; BOUHASSIRA, E. E.; NAGEL, R. L. Polymerase chain reaction amplification applied to the determination of beta-like globin gene cluster haplotypes. Am J Hematol, v. 32, p. 66-9, 1989.
13. VELLA, F. Acid agar gel electrophoresis of human hemoglobins. Am J Clin Path, v. 49, n. 3, p. 440, 1968.

14. VERGER, P. Fluxo e refluxo do tráfico de escravos entre o Golfo do Benin e a Bahia de Todos os Santos: dos séculos XVII a XIX. São Paulo: Corrupio, 1987.

15. WEATHERALL, D. J.; PROVAN, A. B. Red cells. In: Inherited anaemias. Lancet, v. 355, n. 9210, p. 116975, 2000 .

16. ZAGO, M. A.; FIGUEIREDO, M. S.; OGO, S. H. Bantu beta s cluster haplotype predominates among Brazilian blacks. Am J Phys Anthropol, v. 88, n. 3, p.295-98, 1992.

17. ZAGO, M. A.; SILVA, W. A.; FRANCO, R. F. Hemoglobinopathies and other hereditary hematological diseases in the Brazilian population. Journal of the Brazilian Association for the Advancement of Science, v. 51, p. 226-34, 1999.

18. ZAGO, M. A. Considerações gerais. In: Agência Nacional de Vigilância Sanitária (ANVISA). Manual de diagnóstico e tratamento de doenças falciformes. 1. ed. Brasil: Copyright, 2002. Cap. 1; p 7-12. 